\title{
ESTUDIO SOBRE HOR. CARM. II 3. LA INFLUENCIA DE EPICURO
}

\section{F. A. García Romero}

1. La oda II 3 de Horacio representa un claro ejemplo de esos operosa carmina que nuestro poeta decía componer al modo de la abeja ${ }^{1}$. Sin duda, quien desee comentar las siete estrofas de que consta esta poesía, se enfrentará a una obra elaborada y capaz de suscitar un sinnúmero de interpretaciones (privilegio de todo lo «clásico») que reflejan la intrincada conexión de sus partes integrantes.

Pocas ideas originales pueden aducirse teniendo en cuenta los trabajos de Collinge ${ }^{2}$, W. Hering ${ }^{3}$ y, en el I Congreso Andaluz de Estudios Clásicos, de Vicente Cristóbal López ${ }^{4}$, donde además de exponer y revisar las opiniones de los dos primeros se estudia con gran lucidez la completa estructura de la oda.

2. El poema contiene elementos de la filosofía epicúrea, que después desarrollaremos, detectables desde el primer adjetivo: «aequam». Cada estrofa, mediante un procedimiento en esencia fácil, corrobora la idea central que Horacio defiende en este caso, idea que, como veremos, puede subdividirse en dos pensamientos principales: la serenidad ante la muerte irremediable y el goce de la vida. Estos van a ser marcados con precisión gracias a la estructura armónica, evidente $y$, a la vez, encubierta, que la obra presenta.

3. En efecto dicha estructura es la clave de la maestría de la oda. La originalidad de Horacio no reside en la temática. El carpe diem y el elemento simposía$\mathrm{co}^{5}$ (vv. 13-14), el locus amoenus ${ }^{6}$ (vv. 9-12) y la inexorabilidad de la muerte ${ }^{7}$ (v. 4; vv. 25-26) son tópicos muy productivos ya desde los líricos griegos arcaicos.

1 Hor. Carm. IV 2, 27-28, 31-32.

2 «Horaz, Ode, 2, 3. Kompositionskunst und Aussage», Wiener Studien, XIII, 1979, págs. 130-143.

3 «Estructura de Hor. Cam., II, 3», Actas del I Congreso Andaluz de Estudios Clásicos, Jaén, 1981, pág. 164 y ss.

4 Alceo, 63 (Reinach).

5 Cf. Alceo, 63, (Reinach), Teognis, 877 ss.

6 Cf. Platón Phaedr., 230 b;. Lucrecio, II 30.

7 Cf. Píndaro Nem. VII 19. 
Ni siquiera supone esta oda algo innovador dentro de las obras completas de Horacio, pues se encuentran abundantes pasajes paralelos ${ }^{8}$. Por consiguiente, parece que la excelencia de la pieza no está en la elección de temas sino en su «arquitectura».

4. Vicente Cristóbal López en el artículo al que me remito, propone una doble estructura. La más simple y evidente es la bipartita que apunta Collinge, mientras que la estructura mesódica (de núcleo y ondas concéntricas en marcada Ringkomposition) es «menos inmediata y mucho más rica en correspondencias y responsiones» ${ }^{9}$. A lo largo del presente trabajo me referiré a otros recursos que descubre este autor. De acuerdo con la estructura mesódica propuesta, la estrofa central es la verdaderamente importante «de manera que el poeta no tanto pretende hacer hincapié en la moderación que se debe guardar en circunstancias críticas o favorables (temas de la primera estrofa), como en el aprovechamiento de lo placentero que la existencia nos brinda, que es el mensaje de la cuarta estrofa» ${ }^{10}$, según palabras textuales, $y$, se alude a continuación a la perfecta simetría que presenta esta estrofa central con su división en dos partes y con un tricolon «crescendo» en cada una de las dos partes.

5. Sin embargo me resisto a creer que, a raíz de la extraordinaria Ringkomposition del poema, quede únicamente como núcleo principal la estrofa cuarta y que, por ello, el poema preconice en primer lugar el aprovechamiento de los placeres de la vida. Sin duda la estrofa cuarta supone un centro, un eje, (es efectivamente la estrofa central de transición ${ }^{11}$ tan normal en las odas horacianas), pero para mí los temas primordiales, como dije, son dos: la serenidad ante la muerte y el goce de la vida, éste desarrollado en la citada estrofa central, aquél compartido entre la primera y la última. Estas dos estrofas poseen recursos semejantes que, según creo, ayudan a realzarles y a situarlas en el mismo nivel de importancia que la cuarta. En primer lugar en ambas se percibe una clara aliteración de nasales al principio (vv. 1-2: Aequam memento... mentem; v. 25 omnes eodem cogimur, omnium). En las dos, por otra parte, se dan polaridades conceptuales (vv. 1-2: in arduis... in bonis; v. 26 serius ocius; vv. 27-28: exitura...impositura $)^{11}$. En los versos 4 y 28 , los finales de cada estrofa, encontramos moriture e impositura, respectivamente, dos participios ${ }^{12} \mathrm{de}$ futuro activos ocupando un lugar preferente dentro del decasílabo alcaico, donde la parte central de las tres en que suele dividirse se compone generalmente de las siguientes sucesiones: vv - v (moriture) o - vv - v (impositura) (también aparece: vv - v; - vv v). El único recurso métrico digno de notarse en la oda se da en estas estrofas, recurso que cobra más vigor si consideramos el rígido esquema de la estrofa al-

8 Hor. Carm. I 4, 13-14; Carm. II 10, 13-16; Carm. II 11, 17-18; Epist. I 10, 30-31; Sat. II 6, 95-96 etc.

9 Actas del I Congreso Andaluz de Estudios Clásicos, p. 166.

10 Ibídem, pág. 167.

11 Ibídem, pág. 166-167; G. Williams, Tradition and Originality in Roman Poetry, Oxford, 1968, págs. 122-3; Horace, Oxford, 1972, pág. 36: por ejemplo, I, 2, 4, 17; II 7, 8, 14; III 8, 10, 11, 14.

12 Actas del I Congreso Español de Estudios Clásicos, pág. 165. 
caica. Además Horacio se mantiene en los límites métricos más ortodoxos de la estrofa, a pesar de la sinafía, extraña en este poeta, en los versos 27-28 in aeternum / exsilium. En cuanto al contenido existen responsiones interesantes. En la primera estrofa los elementos impresivos, imperativos (v. 1: memento) y vocativo (v. 4: moriture Delli), revelan el llamamiento de que es objeto Delio por parte de Horacio, llamamiento que, individualizado en Delio, es a la vez aseveración general para todos los mortales. En la estrofa séptima la relación es inversa. La afirmación tajante omnes eodem cogimur, omnium versatur urna... sors (vv. 25-27) encubre una advertencia a Delio en su condición de mortal. En ambas estrofas se encuentra a un tiempo la generalización y la individualización. De este modo toman especial relieve tanto omnes del v. 25 como el aequam del v. 1, ambos términos colocados en lugar enfático a principio de verso y ambos recogidos después respectivamente por omnium del v. 25 y temperatam del v. 3 , adjetivo que en el contexto del verso conlleva un significado muy afín a aequam (serenidad y templanza de pasiones ante las circunstancias).

El hecho de que estos dos adjetivos, aequam y temperatam, estén situados dentro de los tres primeros versos demuestra que el poeta tuvo interés especial en resaltarlos. La conexión con el tema de «la serenidad ante la muerte irremediable» es obvia, lo que ocurre es que Horacio ha adelantado la conclusión, es decir, en vez de exponer primero lo cierto y evidente de la muerte para los hombres y, tras el desarrollo escogido, presentar al final la paráinesis, la exhortación a conservar serenidad y templanza, en vez de esto, digo, adelante esta idea, sin duda epicúrea (como luego veremos), a la primera estrofa, ofreciendo así un contrapeso y, a la vez, una reafirmación de la estrofa central, que también hace referencia a Epicuro.

6. Tras haber examinado las estrofas primera, cuarta y séptima, se impone un breve examen de las cuatro que quedan intermedias: la segunda y tercera y la quinta y sexta. ¿Qué papel cumplen dentro de esa estructura sustentada por tres «vigas» principales?

Como característica general de toda la composición se descubren en estas estrofas contraposiciones conceptuales, de las que ya hablamos al referirnos a la primera y la séptima y que pueden también observarse en la cuarta al menos en el contraste del color rosa (v. 14: rosae) y el negro (v. 16: atra). Así pues, en la estrofa segunda se enfrenta maestus (v. 5)/ bearis (v. 7) y omni / tempore (v. 1) / per dies festos (v. 6-7) ${ }^{13}$; en la tercera, elementos verticales (árboles) / elementos horizontales (arroyo); lo mismo ocurre en la quinta, horizontalidad (Tíber) / verticalidad (amontonamientos de riquezas) ${ }^{14}$; y en la sexta también se advierten las contraposiciones divus / pauper, prisco... ab Inacho / infima de gente y sub divo / Orci. Además, la Ringkomposition queda marcada por los motivos paisajísticos que emparejan la tercera y quinta, y las bipolaridades de la estrofa segunda frente a las de la sexta ${ }^{15}$.

13 Ibídem, pág. 166.

14 Ibídem, pág. 167.

15 Ibídem, pág. 164. 
7. Pero el emparejamiento de tercera y quinta por un lado, y segunda y sexta por otro, mediante la composición anular, no es el único que se produce. Al mismo tiempo las estrofas segunda y tercera están conectadas entre sí y a la vez también con la primera y la cuarta; por su parte, la quinta y la sexta forman un bloque compacto relacionado con las estrofas cuarta y séptima. Es decir las estrofas mediales entre los extremos y el centro se encuentran íntimamente unidas a las tres «vigas» maestras de la oda. Evidente es la conexión de las estrofas segunda y tercera por medio de la bipartición en ambas manifestada por la anáfora seu...seu (vv. 5 y 6) y por quo...quid (vv. 9 y 11) respectivamente. También existe un pequeño juego de referencias si pensamos que el locus amoenus descrito en la estrofa tercera está anticipado por el in remoto gramine del v. 6 .

Por su parte la estrofa segunda queda unida a la primera al considerar que los versos 5-8 no son sino un desarrollo explicativo que insiste en lo irremediable de la muerte bien matizada por el moriture del v. $4^{16}$. La estrofa tercera, a su vez, con el tópico del locus amoenus prepara vagamente la escena de la estrofa central y lo mismo ocurre con la quinta que continúa con el motivo paisajístico. Es digno de mención el hecho de que casi los únicos recursos fonéticos de toda la oda se dan en las estrofas tercera y quinta: la aliteración del fonema /l/ y en parte de /r/ para dar viveza a los saltos del agua del arroyo y del Tíber (vv. 11-12: obliquo laborat lympha... trepidare rivo; v. 18: villaque Flavus quam Tiberis lavit), enmarcando así la estrofa cuarta con la resonancia del agua. El hecho que relaciona las estrofas quinta y sexta es el mismo que comentábamos entre la segunda y tercera: la bipartición. Esta viene manifestada por cedes...cedes (vv. 17-19) y por -ne...an (vv. 21-22). También se encuentra entre ellas un juego referencial, ya que el dives del v. 21 recoge divitiis del v. 20. Por último, los términos dives / pauper (vv. 21-22) y la otra oposición existente entre prisco... ab Inacho (v. 21) e infima de gente (vv. 22-23) suponen, como vimos entre moriture (v. 4) y la estrofa segunda, un desarrollo más extenso del omnes generalizador del v. 25 (también Orci en el v. 24 anuncia el eodem del v. 25). Por consiguiente parece que los paralelismos dentro de la oda no sólo gozan de una perfección admirable, sino que se dan en todas direcciones. Sirva como resumen de este examen de la estructura un esquema que muestre los distintos emparejamientos.

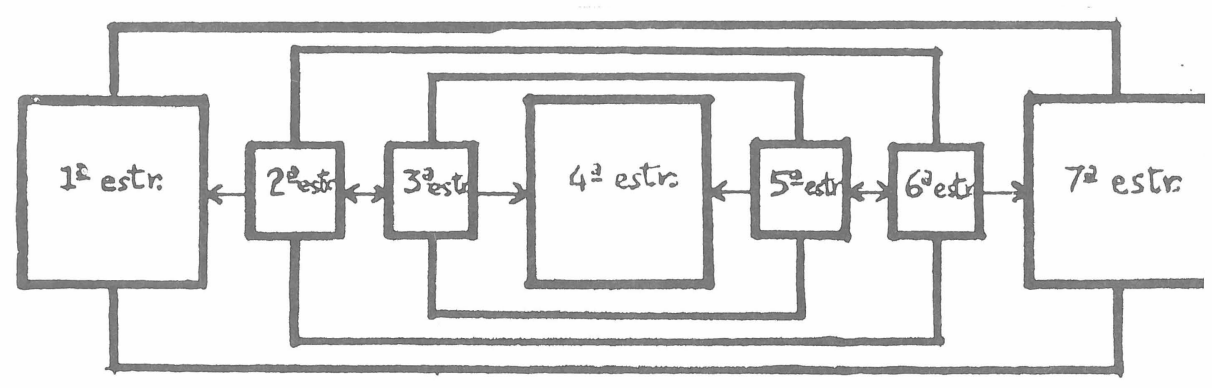

16 Lugar muy descollante porque, aparte de la escogida sedes métrica, ahí se esperaría un adjetivo de elogio o alabanza y no esa expresión. Cf. Syndikus, Die Lyrik des Horaz, I, Darmstadt, 1972, pág. 361 . 
8. Me parece oportuno defender ahora desde otro punto de vista la principalidad de las dos estrofas extremas comparables en importancia a la central, e incluso más significativas que ésta, según creo, si atendemos al contenido verdaderamente epicúreo que se asigna a esta oda. No es mi objetivo, sin embargo, discutir sobre la doctrina ética de Epicuro ni sobre jerarquías en sus diversos pensamientos. Lo que sí es cierto es que los dos temas fundamentales que he propuesto a lo largo del comentario ejemplificados por las estrofas primera y séptima, por un lado (la serenidad ante la muerte irremediable) y la cuarta, por otro (el goce de la vida), cuentan con una clara fuente en la obra de Epicuro, como veremos. Incluso me atrevería a afirmar que la composición es más epicúrea por las dos estrofas representantes del primer tema (primero y séptimo) que por la que manifiesta el segundo (cuarta). Me induce a pensar así sobre todo el aequam y el moriture del verso primero, la insistencia en la generalidad de la muerte del v. 25 (omnes... omnium) y el hecho de que el tema de la estrofa cuarta es un tópico ya desde la lírica griega arcaica (cf. fragmentos vistos de Alceo y Teognis).

9. Tú, Delio, vas a morir y ésta es la ley que a todos obliga. Así pues, ármate de serenidad ante los vaivenes de la fortuna y regálate con los bienes a tu alcance mientras el destino te lo concede. Repasemos, tras este resumen, algunos fragmentos de Epicuro y comprobemos la afinidad de ideas.

- Fr. 339 Us.: «Frente a las demás cosas es posible procurarse seguridad, pero respecto a la muerte todos los hombres habitan una ciudad sin murallas».

Es indiscutible la relación con la estrofa séptima.

-Fr. 488 Us.: «El alma ruin se engríe con la dicha y es abatida por el infortunio»».

- Fr. 489 Us.: «Y la naturaleza enseña a considerar insignificante lo que proviene de la fortuna... y a recibir con serenidad los bienes de la fortuna y a mantenernos firmes contra lo que parecen ser males provenientes de ella».

Compárense los pasajes con la estrofa primera.

Fr. 409 Us.: «Principio y raíz de todo bien es el placer del vientre...»

Recuérdese los vina de la estrofa cuarta y el ambiente de placeres más directos que conllevan los vv. 13-14. Otros podrían aducirse como complemento a los indicados. Horacio desarrolla el tema del primer fragmento en la estrofa séptima y añade un moriture anunciador en la primera. La ataraxía del segundo fragmento escogido viene representada por aequam del v. 1 de la oda. El fragmento último está reflejado por la estrofa cuarta central y por algunos considerada la primordial de la obra (como ya vimos). De acuerdo con las relaciones internas y la composición del poema, las estrofas primera, cuarta y séptima están niveladas en cuanto a la importancia que les otorgó quizás el poeta. Y lo dicho lo considero corroborado atendiendo a las doctrinas epicúreas que Horacio supuestamente expuso en la oda. Puede que para la preferencia mostrada hacia la estrofa cuarta haya influido la parcial y trivializada concepción que se ha tenido sobre Epicuro y sobre sus ideas éticas, olvidando sin duda lo que nos dice Séneca (Epist. 66, 45): «Para Epicuro son dos los bienes de los que se compone la suma felicidad: que el cuerpo esté sin dolor y el alma sin perturbación». A partir de estas palabras podemos deducir que, desde el punto de vista epicúreo, los dos temas de la 
oda tienen importancia semejante. Es más, si hacemos caso a Diógenes Laercio ${ }^{17}$ cuando en X 137 puntualiza que Epicuro consideraba tanto los placeres como los dolores del alma más importantes y graves respectivamente que los del cuerpo, entonces nos es posible sugerir que Horacio, siguiendo a Epicuro en el contenido, pretendió por la forma dar relevancia a estos «dos bienes de la suma felicidad» epicúrea, incluso acentuar por los recursos también formales ya examinados la ansiada imperturbabilidad epicúrea presentándola a Delio como escudo contra el azar y la muerte.

No hay razón para pensar que nuestro poeta en una oda epicúrea quisiera resaltar la idea del goce. No debe creerse que Horacio tuviera un conocimiento tan vulgar del epicureísmo ${ }^{18}$. También la oda I 11, además de contener el tópico del carpe diem (v. 8), muestra otras ideas epicúreas, a saber, la negativa a intentar prever el futuro y la exhortación a soportar con resignación lo que depare la fortuna (vv. 1-8).

10. Horacio, en definitiva, fue capaz de crear en la oda II 3 una monumental obra de arte utilizando unos temas, en parte, $\tan$ viejos como el mundo ${ }^{19} \mathrm{y}$, en parte, difundidos por una filosofía, la epicúrea.

17 Diog. Laer. X 137: «Se diferencia además de los cirenaicos, pues éstos juzgan que los dolores del cuerpo son peores que los de las almas ... él por el contrario juzga peores los dolores anímicos; en todo caso, a la carne la atormenta sólo lo presente; pero al alma lo pasado, lo presente y lo futuro; de este modo, pues, también juzga que son mayores los placeres del alma«.

18 Se reconoce por otra parte que el célebre pasaje en el que Horacio se califica como Epicuri de grege porcum (Epist. I 4, 16) conlleva un claro sentido humorístico. Cf. K. Buechner, «Horace et Epicure», Actes du VIII Congres de l'Association Guillaume Budé, París, 1969, págs. 457-469.

19 Syndikus: op. cit. pág. 361, n. 12. 